\title{
Changes in Motoneuron Properties and Synaptic Inputs Related to Step Training after Spinal Cord Transection in Rats
}

\author{
Jeffrey C. Petruska, ${ }^{1}$ Ronaldo M. Ichiyama, ${ }^{2}$ Devin L. Jindrich, ${ }^{2}$ Eric D. Crown, ${ }^{2}$ Keith E. Tansey, ${ }^{2}$ Roland R. Roy, ${ }^{2}$ \\ V. Reggie Edgerton, ${ }^{2}$ and Lorne M. Mendell ${ }^{1}$ \\ ${ }^{1}$ Department of Neurobiology and Behavior, State University of New York at Stony Brook, Stony Brook, New York 11794-5230, and ${ }^{2}$ Department of \\ Physiological Sciences, University of California, Los Angeles, Los Angeles, California 90095-1527
}

\begin{abstract}
Although recovery from spinal cord injury is generally meager, evidence suggests that step training can improve stepping performance, particularly after neonatal spinal injury. The location and nature of the changes in neural substrates underlying the behavioral improvements are not well understood. We examined the kinematics of stepping performance and cellular and synaptic electrophysiological parameters in ankle extensor motoneurons in nontrained and treadmill-trained rats, all receiving a complete spinal transection as neonates. For comparison, electrophysiological experiments included animals injured as young adults, which are far less responsive to training. Recovery of treadmill stepping was associated with significant changes in the cellular properties of motoneurons and their synaptic input from spinal white matter [ipsilateral ventrolateral funiculus (VLF)] and muscle spindle afferents. A strong correlation was found between the effectiveness of step training and the amplitude of both the action potential afterhyperpolarization and synaptic inputs to motoneurons (from peripheral nerve and VLF). These changes were absent if step training was unsuccessful, but other spinal projections, apparently inhibitory to step training, became evident. Greater plasticity of axonal projections after neonatal than after adult injury was suggested by anatomical demonstration of denser VLF projections to hindlimb motoneurons after neonatal injury. This finding confirmed electrophysiological measurements and provides a possible mechanism underlying the greater training susceptibility of animals injured as neonates. Thus, we have demonstrated an "age-at-injury"-related difference that may influence training effectiveness, that successful treadmill step training can alter electrophysiological parameters in the transected spinal cord, and that activation of different pathways may prevent functional improvement.
\end{abstract}

Key words: spinal cord injury; locomotion; training; activity-dependent plasticity; proprioception; propriospinal; electrophysiology

\section{Introduction}

Locomotor training has been demonstrated to improve stepping ability after a complete spinal cord transection in animal models, including adult and neonatal cat (de Leon et al., 1998a,b; Rossignol, 2000), neonatal rat (Timoszyk et al., 2005), and humans (Harkema, 2001). In general, trained subjects are consistently

Received May 31, 2006; revised Feb. 21, 2007; accepted Feb. 26, 2007.

This work was supported by the Christopher and Dana Reeve Foundation (CDRF) International Research Consortium on Spinal Cord Injury (L.M.M., V.R.E.), the Paralysis Project of America (J.C.P.), and the International Institute for Research on Paraplegia (J.C.P.). Additional support was provided by National Institutes of Health Grant NS16996 (L.M.M.). We thank Maynor Herrera and Alyssa Tuthill for excellent technical assistance and animal care and Aileen Anderson and the staff of the CDRF Animal Core Facility for assistance with the anatomical assays.

Correspondence should be addressed to Dr. Lorne M. Mendell, Department of Neurobiology and Behavior, State University of New York at Stony Brook, 550 Life Sciences Building, Stony Brook, NY 11794-5230. E-mail: Lorne.Mendell@sunysb.edu.

E. D. Crown's present address: Merck Research Laboratories, Pain Research, 770 Sumneytown Pike, P.0. Box 4, WP46-300, West Point, PA 19486. E-mail: eric_crown@merck.com.

K. E. Tansey's present address: Department of Neurology, University of Texas, Southwestern Medical Center, 5323 Harry Hines Boulevard, Dallas, TX 75390-8897.

D. L. Jindrich's present address: University of Arizona, Department of Kinesiology, Physical Education Building East 107B, Tempe, AZ 85287-0404. E-mail: devin.jindrich@asu.edu.

D01:10.1523/JNEUROSCI.2302-06.2007

Copyright $\odot 2007$ Society for Neuroscience $\quad$ 0270-6474/07/274460-12\$15.00/0 able to perform more steps within a given time interval at various speeds. The greater stepping capacity correlates highly with improved electromyographic activity in selected muscles (de Leon et al., 1998a,b). Given that neither changes in muscle properties (Roy and Acosta, 1986; Roy et al., 1998, 1999) nor regeneration of descending tracts (Joynes et al., 1999; Grillner, 2002) could account for the differences in stepping ability after training, these improvements must stem from plasticity of neurons and circuits involved in stepping that are present in the lumbar spinal cord (Grillner, 2002). Little is known, however, about how the spinal circuitry changes in response to training and how specific changes may contribute to the improved motor performance (Cote et al., 2003; Cote and Gossard, 2004).

We examined electrophysiological properties of neural circuits in the spinal cord caudal to a complete transection injury. Comparisons were made between neonatally injured animals that did or did not receive treadmill step training and also between animals injured as neonates or young adults. These experiments reveal differences in electrophysiological parameters that correlate directly with the effectiveness of training in neonatally injured animals and point to factors that may be involved in the 
differing effectiveness of training after neonatal and adult injuries (Ichiyama et al., 2005).

We evaluated the response of ankle extensor motoneurons to a single stimulus or bursts of stimuli delivered to group Ia fibers (stretch receptors) innervating a synergist muscle and to the spinal cord white matter via a microelectrode placed rostrally (but caudal to the transection) in the ipsilateral ventrolateral funiculus (VLF). We also measured the electrical properties of the motoneurons and the amplitude and duration of their action potential (AP) afterhyperpolarization (AHP). To gain additional perspective, we evaluated the same electrophysiological parameters in normal adult rats. An important feature of these experiments was the ability to determine electrophysiological and behavioral parameters in the same neonatally transected animals. This was crucial because of the difference in responsiveness to the training regimen among rats.

We also used anatomical techniques to examine projections of the surviving VLF axons caudal to the transection into the hindlimb motoneuron pool as well as the source of projections to the hindlimb motoneurons in both neonatally and adult-injured rats. These data related very well to electrophysiological data and reveal possible mechanisms underlying the spontaneous recovery of neonatal rats as well as their greater susceptibility to training. Preliminary data from these experiments have been presented previously (Petruska et al., 2004).

\section{Materials and Methods}

These experiments were performed with Institutional Animal Care and Use Committee approval from State University of New York at Stony Brook (SUNY-SB), University of California Irvine (UC-Irvine), and University of California Los Angeles (UCLA). Surgeries for the behavioral/ electrophysiological assays were performed at UCLA as were the behavioral assays and the training. Some trained rats were then shipped by courier to SUNY-SB for electrophysiological assays. Surgeries for the anatomical assays were performed at SUNY-SB and the Christopher Reeve Foundation Animal Core Facility at UC-Irvine. The short-term spinal transections in adults were performed at SUNY-SB.

Surgery. The procedures for neonatal spinal transections have been reported in detail previously (Kubasak et al., 2005). In short, 5-d-old Sprague Dawley female pups were deeply anesthetized, and the dorsal midline skin was incised. After reflecting the paravertebral muscles, a laminectomy was performed between spinal segments T6 and T8. The dura mater was opened, and the spinal cord was completely transected with microscissors. The cut ends of the spinal cord were further separated with small cotton pellets to ensure the completeness of the transection. Gel foam was placed into the gap, and the muscles and skin were sutured in layers.

For the adult transections, female Sprague Dawley rats (150-180 g) were anesthetized with a mixture of ketamine $(80 \mathrm{mg} / \mathrm{kg})$ and xylazine $(8$ $\mathrm{mg} / \mathrm{kg}$ ). The procedure for spinal transection was identical to the one for neonatal rats as described above. After surgery, rats were placed in an incubator $\left(27^{\circ} \mathrm{C}\right)$ until they were responsive.

Spinal transection procedures for the anatomical assays were the same as described above. At $\sim 12-14$ weeks of age, animals were again anesthetized, and a single-segment laminectomy was performed. A small incision was made in the dura mater to allow injection of tracer (for details, see below). Incisions were closed in layers, and the animals were allowed to survive for $4 \mathrm{~d}$, after which they were killed, exsanguinated with heparinized saline buffer, and perfused with $4 \%$ paraformaldehyde.

Step training. For 1 week before the initial training session, all spinal transected rats were familiarized with the task. They were placed in the upper body harness and suspended by a body-weight support (BWS) system while standing on the static treadmill belt for 10-15 min. Locomotor training started at $21 \mathrm{~d}$ of age. In each 15 min training session, their upper bodies were suspended, allowing the rats to assume a bipedal posture. The BWS was automated via a computer, which controlled the amount of support provided by the apparatus based initially on the weight of the rat (Timoszyk et al., 2005). The BWS was then adjusted to each individual rat to produce the best stepping possible. The speed of the treadmill increased progressively from 6 to $21 \mathrm{~cm} / \mathrm{s}$. This progression was determined by the rats' ability to step, which improved with time. Rats were trained $5 \mathrm{~d}$ /week for 6 weeks. By the end of the 6 week training period, most trained rats were able to sustain a speed of $21 \mathrm{~cm} / \mathrm{s}$ for the duration of the 15 min training session.

Behavioral testing and measurements. Step kinematics during test sessions at $21 \mathrm{~cm} / \mathrm{s}$ were analyzed using a video-based system. Reflective markers were placed on the skin over bony landmarks on the rat's hindlimbs: iliac crest, lateral trochanter of the femur, lateral condyle, lateral maleolus, and distal fifth tarsal-metatarsal joint. Video data were collected at $60 \mathrm{~Hz}$ and analyzed for $10 \mathrm{~s}$ of stepping. Joint angular (hip, knee, ankle) and linear kinematics were calculated for each speed as well as step kinematics parameters.

Kinematic analysis. We used several quantitative methods to evaluate treadmill stepping. We counted the number of plantar steps the animal was able to perform. Steps qualified when the plantar surface of the foot contacted the treadmill belt with the toes extended over the entire stance period of a clearly identifiable step. This was ascertained directly from the video records of the stepping trial. We also performed a detailed, jointlevel comparison of stepping kinematics with those observed in uninjured animals, assessed movement coordination among joints, and evaluated the characteristic frequency of the movements.

To perform the comparison of stepping kinematics at each joint, we used an analysis based on the continuous wavelet transform (CWT) (Burke-Hubbard, 1998). Mean angle trajectories for each joint were averaged across five uninjured animals during bipedal hindlimb stepping to yield characteristic movement trajectories for each joint. The angle trajectories were individually normalized to zero mean, and then the set of angle trajectories for each joint was shifted together in phase to minimize the mean angle at the beginning and end of the resulting set of trajectories. The trajectory for each joint was then fitted with a 10thorder polynomial and converted to a reference wavelet using the MATLAB function "pat2cwav" (supplemental Fig. $1 A$, available at www. jneurosci.org as supplemental material). For each stepping trial, the CWT was calculated for each joint angle at a time scale corresponding to the mean stride duration observed during stepping by noninjured animals (supplemental Fig. $1 B, C$, available at www.jneurosci.org as supplemental material). Positive CWT coefficients indicate a positive correlation between the angular movements of the joint and its reference wavelet, an index of the similarity of the stepping kinematics around that time point to that of noninjured animals stepping at that rate. The meansquared value of the positive wavelet coefficients (negative coefficients were set to zero) was calculated over the entire time series for each joint. These mean-squared values were summed across individual joints of each hindlimb of each animal to yield a wavelet resemblance (WR), considered a measure of the degree to which the three joints together exhibited step-like kinematics over the entire trial. The WR thus does not reflect the coordination among leg joints. Step-like movements of larger amplitude lead to higher WR values than smaller movements.

To assess the coordination among leg joints during locomotion, we used an analysis based on the cross-correlation function. Crosscorrelations among all pairs of joints were calculated over a time lag range corresponding to \pm 2 times the average stride period for noninjured animals stepping at $21 \mathrm{~cm} \mathrm{~s}^{-1}$ (supplemental Fig. $1 D$, available at www. jneurosci.org as supplemental material). The peak correlations (absolute values) for each of the three joint pairs were averaged to yield an index of joint coordination for the leg, the peak cross-correlation (PXC). The PXC reflects the consistency of coordination among joints, even if joint movements are offset in time. The PXC is less sensitive to the extent to which the specific kinematic waveforms are similar to normal stepping apart from differences in range of movement. Consequently, although the PXC and WR both increase for larger movements, they measure primarily independent aspects of stepping kinematics.

To evaluate movement frequency, we calculated the power spectrum for each joint angle time series using the fast-Fourier transform and identified the frequency at peak power (FPP) (supplemental Fig. 1E, 
available at www.jneurosci.org as supplemental material). We consider the average of the peak power (over all joints) as a description of the overall movement frequency for the leg.

Electrophysiology. Electrophysiological experiments were performed not $>10 \mathrm{~d}$ after rats left UCLA. Previous evidence in cats suggests that the effects of training are maintained for this length of time (De Leon et al., 1999). Five groups of rats were analyzed: (1) rats receiving neonatal [postnatal day 5 (P5)] transection (TX) and not trained $(n=8),(2)$ rats receiving neonatal transection and treadmill step training $(n=10),(3)$ rats receiving spinal cord transection as young adults ( 5 weeks of age) and not trained but surviving for $4-6$ weeks $(n=5),(5)$ intact adults $(n=7)$, and (5) rats receiving transection as adults but surviving only $4 \mathrm{~d}(n=2)$ to compare the acute and chronic effects of adult spinal transection. The experiments on neonatally transected step-trained rats were performed blind to the results of the behavioral analyses. One of the animals used for behavioral analysis was not studied electrophysiologically.

Rats were anesthetized with ketamine/xylazine $(80 / 10 \mathrm{mg} / \mathrm{kg})$ and intubated via the jugular vein for supplemental anesthesia and via the trachea to monitor end-tidal $\mathrm{CO}_{2}$ and for artificial ventilation, if necessary. A laminectomy was performed to expose the lumbar enlargement, the L4/5 dorsal roots, and the T10/11 spinal cord segments. The L4/5 roots were gently held with bipolar electrodes for incontinuity recordings of the afferent volley.

The medial gastrocnemius (MG) and lateral gastrocnemius/soleus (LGS) nerves were exposed, dissected free, transected close to the muscles, and placed on bipolar hook electrodes. The posterior biceps and semitendinosus, common peroneal, and remaining tibial nerve branches were either transected or crushed.

A glass microelectrode $(15-30 \mathrm{M} \Omega ; 3 \mathrm{M} \mathrm{KCl}$ ) was lowered into the L4/5 spinal cord to search for MG or LGS motoneurons, identified by the presence of an antidromic AP in response to stimulation of the nerve. Stimulus pulses were delivered to the ipsilateral VLF at approximately T11 by a monopolar tungsten electrode, with the other lead placed in the ipsilateral thoracic muscle ( 6 of 8 neonatal-TX nontrained; 8 of 10 neonatal-TX trained; all adult-TX and intact) (Fig. 1). To normalize VLF stimulation across experiments, stimulus intensity was set to two times threshold for eliciting a detectable EPSP in motoneurons. We confirmed the absence of stimulus spread to sensory fibers on the dorsal columns by demonstrating no antidromic response on L4/5 dorsal roots from VLF stimulation, and that the VLF-evoked response in single motoneurons was not affected by crushing the dorsal columns $5-10 \mathrm{~mm}$ caudal to the VLF electrode.

At the end of the experiment, animals were killed with an overdose of urethane. A gross-level examination of the transection region confirmed no overt sparing of spinal cord tissue. In all cases, connective tissue (often calcified) was found in the injury core.

Analysis. Only records from motoneurons with resting membrane potential between -60 and $-80 \mathrm{mV}$ (corrected after withdrawal from the cell) and an AP amplitude of $>60 \mathrm{mV}$ were included. All measures (except rheobase) were taken from traces generated from averages of multiple (4-20) trials. Not all cells had all measures taken.

Rheobase current and input resistance were determined from the response to intracellular depolarizing current injections. To measure characteristics of the AHP, an intracellular action potential was generated by delivering a brief depolarizing pulse. AHP-depth (AHPd) was measured from baseline to the lowest point of the AHP, and the time to halfrecovery (AHP50) was measured from that point to the time where membrane potential returned halfway to baseline. The maximum synaptic EPSP produced by single shock and short high-frequency burst stimulation of spindle afferent (group Ia) fibers in the heteronymous nerve (MG afferent to LGS motoneuron, and vice versa) [segmental EPSP (sEPSP)] was recorded. Similar stimulus patterns were delivered to the ipsilateral VLF at a strength of twice the response threshold (2T), and the EPSP [central EPSP (cEPSP)] was recorded. Bursts consisted of five pulses at 100 and $200 \mathrm{~Hz}$ repeated at $0.5-1 \mathrm{~Hz}$. The synaptic response to single shock stimulation of VLF was separated into monosynaptic and polysynaptic components. The amplitude of the polysynaptic EPSP was calculated by subtracting the amplitude of the monosynaptic component from the overall peak. For measures of facilitation during the burst, the

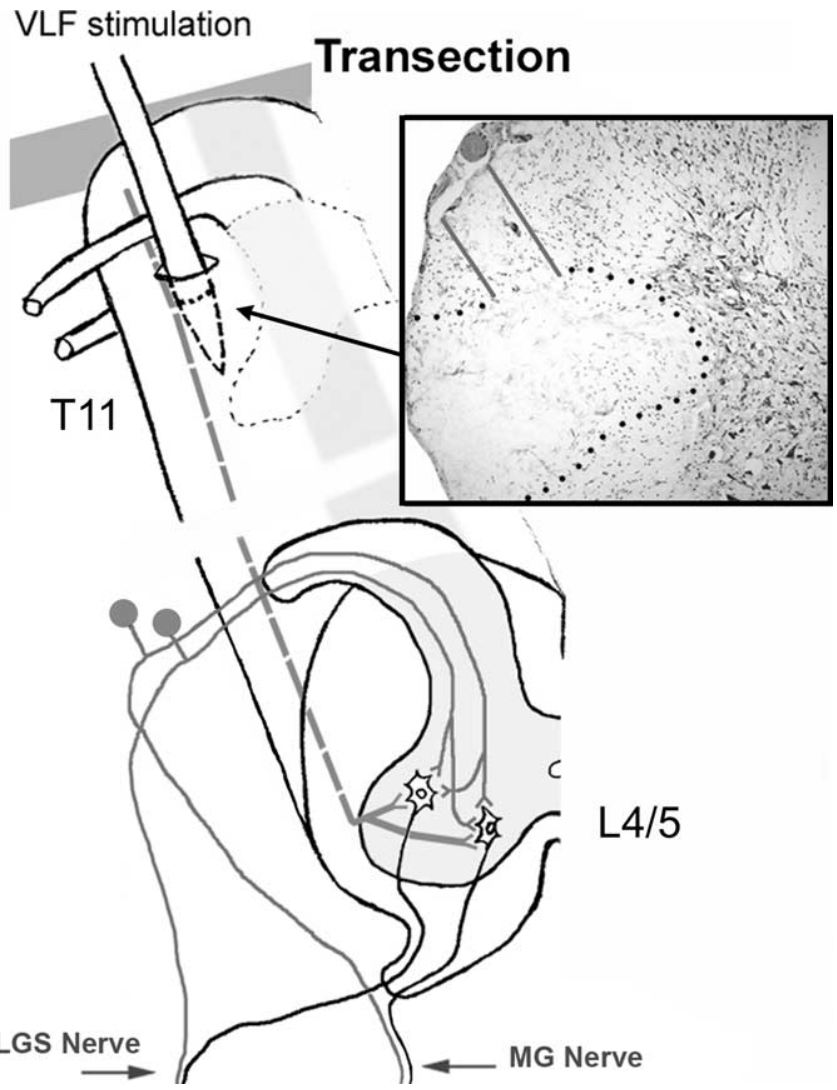

Figure 1. Schematic of the experimental preparation demonstrates the placement of the ipsilateral VLF electrode in the T11 cord and the heteronymous and homonymous monosynaptic connections of the stretch-reflex afferents from the MG and LGS nerves onto the corresponding motoneurons at $\mathrm{L} 4 / 5$. The inset shows a Nissl-stained tissue section where an electrolytic lesion was created to reveal the area of the spinal cord stimulated by the VLF electrode (dorsal at top; midline at right). The gray lines indicate the electrode track, and the dotted lines indicate the largest possible stimulation zone.

amplitude from baseline to peak was measured, regardless of whether that peak was a monosynaptic or polysynaptic response. Percentage facilitation was calculated as follows: $\left[\left(\mathrm{cEPSP}_{5}-\mathrm{cEPSP}_{1}\right) / \mathrm{cEPSP}_{1}\right]^{*} 100$.

Anatomy. Surgical approaches were performed as described above. Tracer injections were performed with a microliter syringe (Hamilton, Las Vegas, NV) attached to a glass pipette, which was positioned in the cord with a micromanipulator. Two different anatomical assays were performed.

Assay (1) used nontrained animals injured at ages (P5 and 5 weeks) similar to those used for electrophysiological studies and examined the location of neuronal cell bodies, particularly in the lumbar enlargement, the axons of which ascended in the VLF and whether such cells had axons projecting directly into the MG motoneuron pool. Dextran-AlexaFluor $594[2 \%, 10 \mathrm{k}$ molecular weight (MW); Invitrogen, Carlsbad, CA] was injected into the left T10/11 lateral white matter and VLF (neonatal injury, $n=4$; adult injury, $n=3$ ), the location of the stimulating electrode in electrophysiological experiments. Volumes were $1 \mu \mathrm{l}$ (for all neonatally transected) and 1-4.5 $\mu \mathrm{l}$ (for adult transected) injected over $20 \mathrm{~min}$. The MG motoneuron pool [identified by intramuscular injection of $10-20 \mu \mathrm{l}$ of $2 \% 10 \mathrm{k}$ MW dextran-Lucifer yellow (LY); Invitrogen)] was examined in horizontal sections (cryostat cut $16 \mu \mathrm{m}$ sections) for retrogradely labeled neurons and axons. The VLF at the rostral end of the labeled motoneurons was also examined to control for the number of VLF fibers stained by the dextran (see Fig. 8).

Assay (2) used nontrained animals injured as young adults and was intended to determine the location of somata at the level of the VLF stimulating electrode (T10/11) with descending projections into the region of the MG motoneuron pool $(n=3)$. Dextran-AlexaFluor 594 (as 
Table 1. Summary of motoneuron and synaptic property data for various groups

\begin{tabular}{|c|c|c|c|c|c|c|c|c|c|c|}
\hline & $E_{\mathrm{m}}(\mathrm{mV})$ & Rheo (nA) & $R_{\mathrm{n}}(\mathrm{M} \Omega)$ & AHP50 (ms) & AHPd (mV) & sEPSP (mV) & $\mathrm{CEPSP}_{\text {mono }}(\mathrm{mV})$ & CEPSP $_{\text {poly }}(\mathrm{mV})$ & SEPSP $\Delta(\%)$ & CEPSP $\Delta(\%)$ \\
\hline tact & $\begin{array}{l}-68.8 \\
( \pm 0.0)(7)\end{array}$ & $\begin{array}{l}8.3 \\
( \pm 0.9)(7)\end{array}$ & $\begin{array}{l}1.7 \\
( \pm 0.4)(5)\end{array}$ & $\begin{array}{l}17.9 \\
( \pm 1.8)(7)\end{array}$ & $\begin{array}{l}1.5 \\
( \pm 0.2)(7)\end{array}$ & $\begin{array}{l}1.6 \\
( \pm 0.8)(7)\end{array}$ & $\begin{array}{l}2.2 \\
( \pm 0.8)(7)\end{array}$ & $\begin{array}{l}0.1 \\
( \pm 0.1)(7)\end{array}$ & $\begin{array}{l}10.7 \\
( \pm 13.5)(7)\end{array}$ & $\begin{array}{l}57.7 \\
( \pm 57.7)(7)\end{array}$ \\
\hline dult-TX & $\begin{array}{l}-68.3 \\
( \pm 1.4)(5)\end{array}$ & $\begin{array}{l}9.3 \\
( \pm 2.8)(5)\end{array}$ & $\begin{array}{l}2.1 \\
( \pm 0.3)(5)\end{array}$ & $\begin{array}{l}16.6 \\
( \pm 1.2)(5)\end{array}$ & $\begin{array}{l}2.3 \\
( \pm 0.6)(5)\end{array}$ & $\begin{array}{l}1.3 \\
( \pm 0.3)(5)\end{array}$ & $\begin{array}{l}0.5 \\
( \pm 0.2)(5)\end{array}$ & $\begin{array}{l}0.1 \\
( \pm 0.1)(5)\end{array}$ & $\begin{array}{l}15.3 \\
( \pm 12.1)(5)\end{array}$ & $\begin{array}{l}84.0 \\
( \pm 16.1)(5)\end{array}$ \\
\hline $\begin{array}{l}\text { eonatal-TX } \\
\text { nontrained }\end{array}$ & $\begin{array}{l}-68 \\
( \pm 3.4)(8)\end{array}$ & $\begin{array}{l}6.5 \\
( \pm 2.2)(8)\end{array}$ & $\begin{array}{l}1.9 \\
( \pm 0.7)(5)\end{array}$ & $\begin{array}{l}18.5 \\
( \pm 4)(8)\end{array}$ & $\begin{array}{l}2.7 \\
( \pm 1.1)(8)\end{array}$ & $\begin{array}{l}1.2 \\
( \pm 0.4)(7)\end{array}$ & $\begin{array}{l}1.3 \\
( \pm 0.6)(6)\end{array}$ & $\begin{array}{l}0.03 \\
( \pm 0.1)(6)\end{array}$ & $\begin{array}{l}3.7 \\
( \pm 7.6)(7)\end{array}$ & $\begin{array}{l}142.3 \\
( \pm 65.2)(6)\end{array}$ \\
\hline $\begin{array}{l}\text { Trained } \\
\text { good-stepper }\end{array}$ & $\begin{array}{l}-68.9 \\
( \pm 2)(8)\end{array}$ & $\begin{array}{l}7.2 \\
( \pm 1.4)(8)\end{array}$ & $\begin{array}{l}2.2 \\
( \pm 0.4)(6)\end{array}$ & $\begin{array}{l}18.9 \\
( \pm 3)(8)\end{array}$ & $\begin{array}{l}1.9 \\
( \pm 0.5)(8)\end{array}$ & $\begin{array}{l}2.2 \\
( \pm 0.7)(8)\end{array}$ & $\begin{array}{l}1.1 \\
( \pm 0.5)(6)\end{array}$ & $\begin{array}{l}0.3 \\
( \pm 0.2)(6)\end{array}$ & $\begin{array}{l}6.9 \\
( \pm 7.0)(8)\end{array}$ & $\begin{array}{l}161.1 \\
( \pm 88.3)(6)\end{array}$ \\
\hline $\begin{array}{l}\text { rained } \\
\text { poor-stepper }\end{array}$ & $\begin{array}{l}-67.7 \\
( \pm 2.6)(2)\end{array}$ & $\begin{array}{l}5.7 \\
( \pm 1.3)(2)\end{array}$ & $\begin{array}{l}2.6 \\
( \pm 0.9)(2)\end{array}$ & $\begin{array}{l}19.8 \\
( \pm 2.8)(2)\end{array}$ & $\begin{array}{l}2.5 \\
( \pm 0.9)(2)\end{array}$ & $\begin{array}{l}1.1 \\
( \pm 1)(2)\end{array}$ & $\begin{array}{l}0.4 \\
( \pm 0.1)(2)\end{array}$ & $\begin{array}{l}0.7 \\
( \pm 0.3)(2)\end{array}$ & $\begin{array}{l}4.8 \\
( \pm 7.5)(2)\end{array}$ & $\begin{array}{l}610.0 \\
( \pm 341.7)(2)\end{array}$ \\
\hline
\end{tabular}

Mean $\pm S D$ (number of animals). $E_{\mathrm{m}}$, Resting membrane potential; Rheo, rheobase current; $R_{n}$, input resistance; AHP50, AHPd $-50 \%$ recovery and depth, respectively, of the AP AHP after intracellular stimulation; $5 E P S P$, amplitude of the

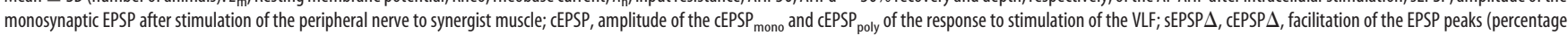
change) during a $100 \mathrm{~Hz}$ stimulus train (5 pulses).

above) was injected into the left MG motoneuron pool. The T10/11 segments were then examined for labeled neurons and axons in $16 \mu \mathrm{m}$ cryostat-cut cross sections.

Quantitative image analysis was performed on sections from Assay 1 to determine the density of labeled VLF processes in the vicinity of labeled motoneurons (neonatal injury, $n=4$ animals, 42 motoneurons in 27 images; adult injury, $n=3$ animals, 39 motoneurons in 21 images). Sections were viewed with a Zeiss (Thornwood, NY) Axiophot microscope with appropriate fluorescence filters (Omega Optical, Brattleboro, VT) through a $40 \times$ dry objective. Images were captured with a Spot 2 digital camera and analyzed with ImagePro Plus software (Media Cybernetics, Silver Spring, MD). A frame of $160 \mu \mathrm{m}^{2}$ was applied to ventral horn gray matter areas centered over individual LY-labeled MG motoneurons (one area per labeled motoneuron). Images of the dextranlabeled VLF axons were uniformly threshold-transformed and the resulting signal expressed as a percentage of the total frame area.

Statistics. Except as noted, we averaged the value of each parameter tested over all motoneurons recorded in an individual rat. These means were averaged over all rats in each group and then compared between treatments (intact, neonatal transection without training, etc.). In most cases, we compared differences between treatments using one-way ANOVA followed by (if significant differences were observed and the data were normally distributed) pairwise comparison using StudentNewman-Keuls that adjusts for multiple comparisons. The degrees of freedom were thus calculated from the number of animals, not the total number of cells recorded (unless necessary because of too few animals in a particular group, as reported in our study). To be included in the overall analysis, a given measure had to be obtained from at least two motoneurons in a given animal. Thus, the number of rats included in any given measure may be lower than the total number in a treatment group if we did not obtain that measurement from at least two motoneurons in a particular rat. The number of rats in each sample was generally six to eight (Table 1). Each variable analyzed in this way passed the normality test as required by the parametric analysis. The value of $\alpha$ was set at 0.05 . When data were not normally distributed, an analogous nonparametric procedure (Kruskal-Wallis followed by the Dunn method) was used, as noted in this study. In cases where only two treatments were being compared, we used either a $t$ test or Mann-Whitney rank sum test depending on the normality of the data. All means are presented \pm SD.

\section{Results}

\section{Stepping behavior}

Overall, spinal transected, trained rats performed more steps than transected, nontrained rats. However, two of the neonatally injured, trained rats were later found to display electrophysiological parameters that distinguished them from all remaining rats. Both of these rats were also unique in the transient presence of lesions on their hindpaws during training. When the experimental codes were broken, we found these two rats performed very few steps compared with all other neonatally transected trained rats and that these steps were poorly coordinated (Fig. 2), unlike all remaining trained rats (see below). These two rats are considered to be a separate group: trained poor-stepper. They more closely resembled the nontrained animals in the number of steps they took $(3.5 \pm 0.7, n=2$ vs $1.6 \pm 2.1$ in the nontrained, transected group). The mean number of left-side steps (13.6 \pm 3.8) for the remaining trained rats, referred to as good-steppers, was significantly higher $(p<0.05)$ than for the nontrained group $(1.6 \pm 2.1)$. Step height was significantly lower in the trained poor-steppers than in either trained good-steppers or nontrained rats ( $p<0.05$; Kruskal-Wallis and post hoc Dunn's method). However, there were no significant differences in other step parameters such as stance duration, swing duration, and step length between trained and nontrained rats.

\section{Stepping kinematics}

The most noticeable difference in the effects of the training regimen was in the consistency of the stepping patterns. This is demonstrated in three-dimensional plots of the instantaneous ankle, knee, and hip joint angles measured over several successive steps (Fig. 2). The stick-figure step reconstructions (Fig. 2) provide a representative example of a trained good-stepper animal that was better able to lift its foot than the representative nontrained or trained poor-stepper. The trained good-stepper group had a significantly greater range of knee joint angle during steps than the trained poor-steppers or nontrained rats $(p<0.01$; KruskalWallis ANOVA on ranks). The ankle and hip joints exhibited no significant differences according to training regimen.

Quantitative analysis of stepping using WR for step shape and PXC for interjoint coordination revealed that the trained poorsteppers differed from the trained good-steppers in exhibiting poorer steps and less joint angle coordination (supplemental Fig. 2 , available at www.jneurosci.org as supplemental material). The trained poor-steppers showed kinematic characteristics closer to the nontrained animals than to the trained good-steppers. Similarly, the trained good-steppers exhibited better coordination (by PXC) and step shape (by WR) than nontrained rats, particularly for the right hindlimb (Kruskal-Wallis, $p<0.05$ for both comparisons). FPP values measuring the frequency at which maximum power was exerted did not show significant differences among the groups in either the right leg or the left leg. However, some suggestion of the effect of the training regimen on frequency of movement was the finding that leg movements exhibiting the highest value of FPP were of significantly lower frequency in nontrained animals $(4 \mathrm{~Hz})$ than in trained goodsteppers ( $9 \mathrm{~Hz}$; Kruskal-Wallis, $p<0.05$ ).

Although nontrained animals did exhibit step-like movements when placed on the treadmill, and identifiable steps did 
not differ from step-trained rats in some parameters, the overall movements of nontrained rats showed less normal kinematics, poorer joint coordination, and lower movement frequencies than trained rats. Cumulatively, these differences resulted in significantly more successful plantar steps for the trained group.

\section{Electrophysiology}

Intact rats

Properties of triceps surae motoneurons and segmental EPSPs (Table 1) were similar to those reported previously (Gardiner and Kernell, 1990; Gardiner, 1993; Seburn et al., 1994), and the proportion of cells in each group with an AHP50 $>20 \mathrm{~ms}$ [an indicator of small/slow motoneurons in the rat (Gardiner and Kernell, 1990)] was similar between all groups (intact, 25\%; neonatal-TX nontrained, $20.1 \%$; trained good-stepper, $25.6 \%$; trained poor-stepper, $33.3 \%$ ). EPSPs elicited by bursts of VLF stimulation followed high-stimulation rates $(100,200 \mathrm{~Hz})$ with little latency and amplitude jitter of the initial component, suggesting the projections included monosynaptic connections. Nearly every cell also exhibited facilitation of VLF EPSPs; in most cases, this also included the recruitment of longer latency components, presumably polysynaptic, in response to later stimuli in the burst. Only rarely was an IPSP detected after VLF stimulation, but the microelectrodes were not optimal to record these. Segmental EPSPs exhibited facilitation or depression during successive stimuli of a burst, but these fluctuated in a narrow range (100 $\mathrm{Hz} \pm 20 \% ; 200 \mathrm{~Hz}, 0-50 \%)$.

Injured rats: electrophysiological differences between rats transected as neonates and as adults

Neonatally injured rats did occasionally step without training, although poorly, but were highly responsive to treadmill step training. This is in contrast to rats injured as adults, which generally do not step well in response to treadmill step training alone (Ichiyama et al., 2005). Because of this marked difference in stepping performance and responsiveness to training, we examined some of the electrophysiological differences between adult rats spinalized as neonates or as young adults ( 5 weeks of age; survival time of 4-6 weeks). Motoneuron properties in rats receiving a complete transection as adults differed little from those in either normal intact rats or neonatally injured rats (Fig. 3, Table 1).

The most notable difference between adult rats transected as neonates or as adults was in the amplitude of the monosynaptic component of the EPSP elicited by VLF stimulation ( $\left.\mathrm{cEPSP}_{\text {mono }}\right)$. In rats transected as neonates, these were approximately half the amplitude of those from intact rats $(1.3 \pm 0.6 \mathrm{mV}, n=6$ vs $2.2 \pm$ $0.8 \mathrm{mV}, n=7 ; p<0.02$ ) (Fig. 3, Table 1), presumably reflecting degeneration of fibers descending from above the lesion. Amplitude of the $\mathrm{CEPSP}_{\text {mono }}$ was even smaller in rats injured as adults

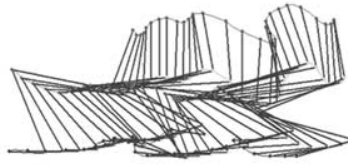
$1120 \quad$ Non-trained $60 \vee$

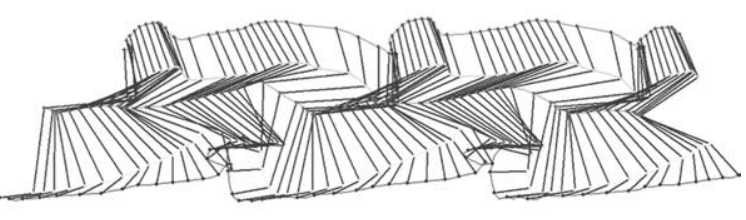

Trained - good

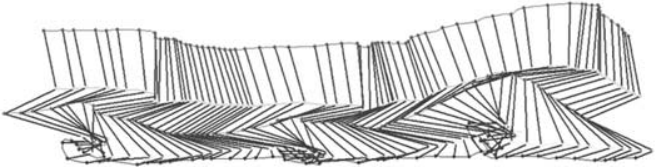

Trained - poor

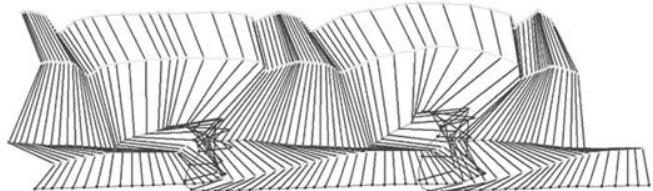

Normal

Figure 2. Relative joint-angle plots (left) and step reconstruction (right) reveal the effects of successful training on treadmill (black arrow) phases are indicated on the plots from the normal and trained good-stepper rats. These behavioral elements were too inconsistent for such indicators in the other groups. Axes of all plots have a range of $90^{\circ}$ (hip, knee) or $160^{\circ}$ (ankle), although the minimum-maximum (hip, knee) are slightly different for the normal animal.

than in those injured as neonates $(0.5 \pm 0.2 \mathrm{mV}, n=5 \mathrm{vs} 1.3 \pm$ $0.6 \mathrm{mV}, n=6 ; p<0.001$ ) (Table 1). Thus, the strength of the VLF input to motoneurons depends on when the injury occurred, perhaps because of the plasticity of the neonatal spinal cord (see below, Anatomy). The limited plasticity of the VLF projection in the adult is demonstrated by the similar magnitude of the cEPS$\mathrm{P}_{\text {mono }}$ after short-term (4 d) and long-term (5-6 weeks) transection (Fig. 3). Unlike the VLF projection, there was no difference in the sEPSP between rats transected several weeks earlier as neonates or as adults (Fig. 3, Table 1), suggesting that the plasticity in the VLF connection inferred from differences in cEPSP $_{\text {mono }}$ amplitude was not attributable to a generalized change in motoneuron properties.

Injured rats: electrophysiological differences between trained and nontrained rats injured as neonates

As mentioned above, two neonatally injured rats stepped poorly despite training. The most striking electrophysiological characteristic of these rats was the high degree of facilitation of the 


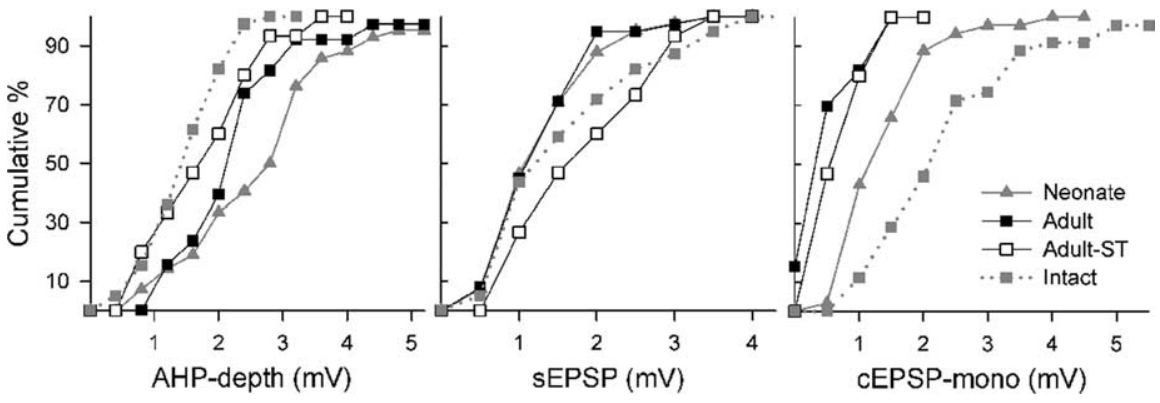

Figure 3. The effect of spinal transection on cellular and synaptic parameters depends on age at transection (neonate vs adult). Motoneuron and synaptic properties from intact, neonatal-transected nontrained (Neonate), adult-transected (Adult), and adulttransected short-term recovery (Adult-ST) groups are displayed as cumulative sum histograms [pooled data from all animals in a group are plotted to demonstrate the percentage of values ( $y$-axis) falling below a particular value ( $x$-axis)]. These histograms represent data from all individual cells pooled over all experiments of a given type, whereas statistical comparisons in the Results were derived from means calculated from each animal. AHPd is increased by injury with neonate $>$ adult $>$ adult-ST. SEPSP is decreased slightly by long-term injury (either neonate or adult) but increased slightly by short-term injury in the adult. The monosynaptic component of the VLF EPSP (cEPSP-mono) is decreased substantially after both short- and long-term transection in the adult and decreased to a lesser extent after neonatal injury.

cEPSP during high-frequency stimulation of the VLF (Fig. 4). In fact, it was this facilitation that initially led us to consider that they might be different from the other trained rats, because we were unaware of their stepping ability during initial analysis of the electrophysiological parameters. These two rats were the only rats from any group displaying this high degree of facilitation of the cEPSP.

One possible source of this facilitation was the presence of unique polysynaptic circuitry activated by VLF stimulation in trained poor-steppers. If different circuitry or inputs were involved, EPSP parameters could be expected to reflect such differences. To test this possibility, we measured the time-to-peak of the EPSPs. Time-to-peak of the combined monosynaptic and polysynaptic cEPSPs in response to single VLF stimuli was significantly greater in the trained poor-steppers ( $4.5 \pm$
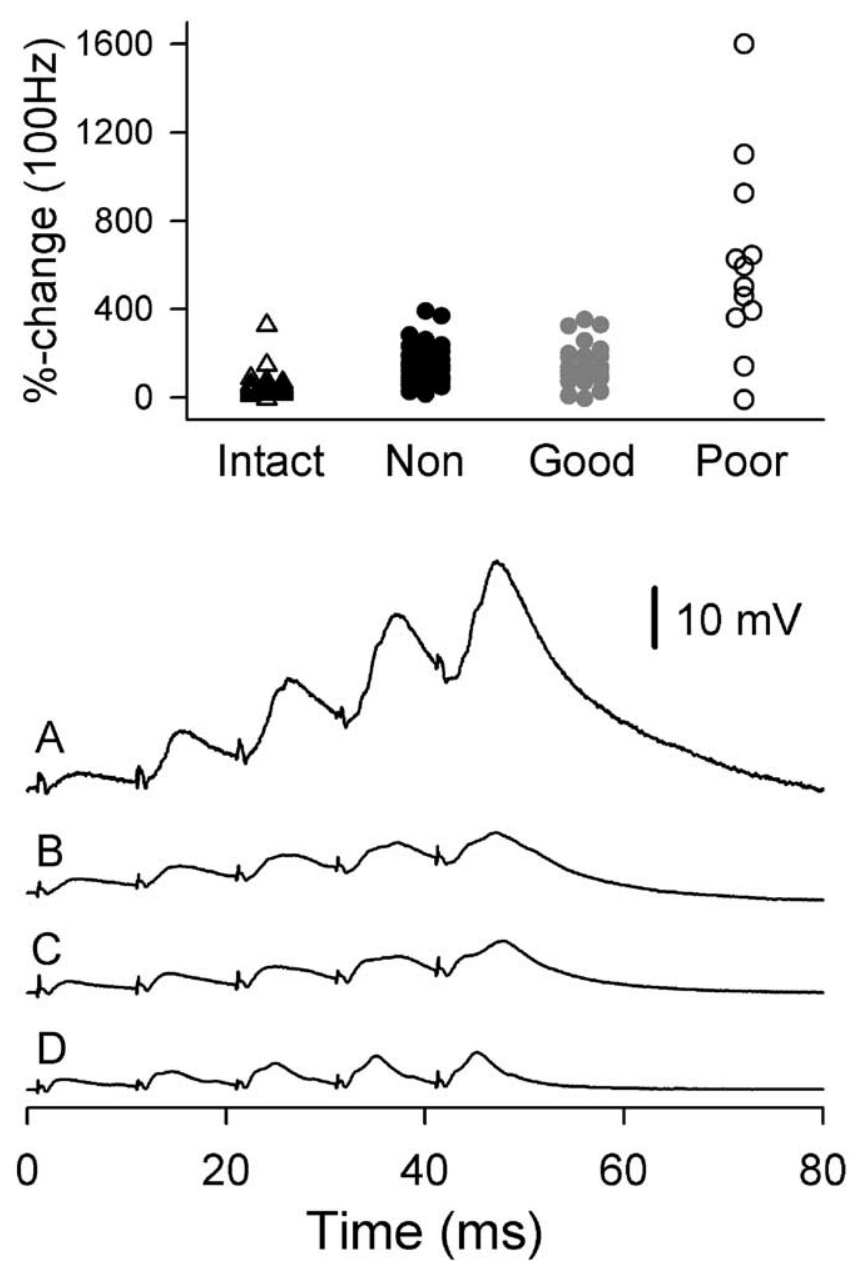

Figure 4. Neonatally transected trained poor-stepper rats display a unique electrophysiological signature. The top panel shows the change in peak amplitude, in all recorded motoneurons, of the fifth EPSP (expressed as a percentage of the amplitude of the first EPSP) elicited by $100 \mathrm{~Hz}$ burst stimulation of the VLF. Note that most EPSPs in poor-steppers are potentiated to a greater degree than the maximum level in all the other preparations. The bottom panel displays records from the cell displaying the greatest facilitation in each treatment group. Groups: $D$, intact; $C$, neonatal-TX nontrained; $B$, trained good-stepper; $A$, trained poor-stepper. Traces are normalized with respect to the first EPSP.
$2.2 \mathrm{~ms}, n=15)$ than in trained good-steppers $(3.3 \pm 1.0 \mathrm{~ms} ; n=$ $29 ; p=0.006$; Mann-Whitney rank sum test from individual cells rather than animal means because of the small number of trained poor-steppers), a difference that did not vary consistently with measures related to cell type (rheobase, AHP50). Thus, VLF polysynaptic circuitry associated with poor stepping after treadmill training is different from that associated with traininginduced good stepping (Fig. 4). The stepping performance (Fig. 2) and electrophysiological characteristics of the cEPSPs (Fig. 4) together indicate that these two rats constitute a distinct group.

Spinal transection in neonates induced a significant increase in mean AHPd (from $1.5 \pm 0.2 \mathrm{mV}, n=7$, in intact rats to $2.7 \pm$ $1.1 \mathrm{mV}, n=8$, after injury; $p<0.02$ ) (Table 1). The effect of transection on AHPd was not systematically related to motoneuron resting membrane potential. Training that led to good stepping reduced mean AHPd so that AHPd for trained good-stepper rats $(1.9 \pm 0.5 \mathrm{~ms} ; n=8)$ no longer differed significantly from AHPd in intact rats $(1.5 \pm 0.2 ; p>0.2)$ (Fig. 4 , Table 1$)$. There was no indication of systematic training-induced changes in other motoneuron parameters (Table 1).

Neonatally transected, nontrained rats exhibited a small, nonsignificant $(p>0.5)$ decline in the amplitude of the sEPSP (Fig. 5 , Table 1). This decline was more than reversed by successful training such that the mean sEPSP was now significantly greater than the mean sEPSP in neonatally transected nontrained rats $(2.2 \pm 0.7 \mathrm{mV}, n=8$ vs $1.2 \pm 0.4 \mathrm{mV}, n=7 ; p<0.03)$. This increase in sEPSP amplitude did not occur in the trained poorstepper group (Fig. 5).

VLF fibers surviving a spinal transection (i.e., with cell body caudal to the transection) made monosynaptic and polysynaptic connections onto motoneurons. The amplitude of the cEPSP did not differ between neonatal-transected nontrained and trained good-steppers $(p>0.5)$ (Fig. 5). However, the polysynaptic component [defined as (peak - monosynaptic)] $\left(\mathrm{cEPSP}_{\text {poly }}\right)$ was significantly larger in neonatally injured trained good-steppers than in nontrained animals $(0.3 \pm 0.2 \mathrm{mV}, n=6$ vs $0.03 \pm 0.01 \mathrm{mV}, n=6 ; p<0.01$ ) (Fig. 5). The proportion of cells in each group with a detectable polysynaptic component after single-shock stimulation also increased with training (nontrained, 20\%; trained good-steppers, 76\%). 

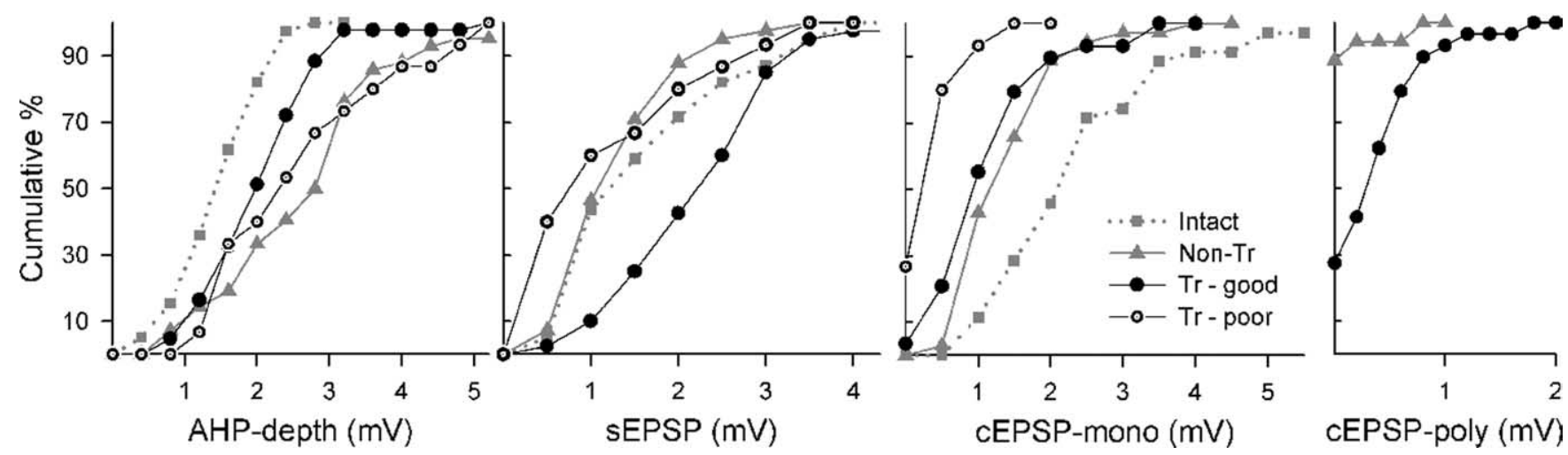

Figure 5. Motoneuron and synaptic properties in neonatally transected rats are affected by training and vary with success of the training. Graphs display cumulative sum histograms of motoneuron and synaptic properties from intact, neonatal-transected nontrained (Non-Tr), trained good-stepper (Tr-good), and trained poor-stepper (Tr-poor) groups. Histograms are from all individual cells in each group (as described in Fig. 3), and symbols used for plots are shared with Figure 3. AHPd is increased by injury and is returned toward normal with successful training. SEPSP is reduced in groups that did not step well, whereas successful training increased the sEPSP above values in intact preparations. The monosynaptic component of the VLF EPSP (cEPSP-mono) was reduced in all groups (although to differing degrees), but successful training increased the polysynaptic component (cEPSP-poly) compared with nontrained animals.

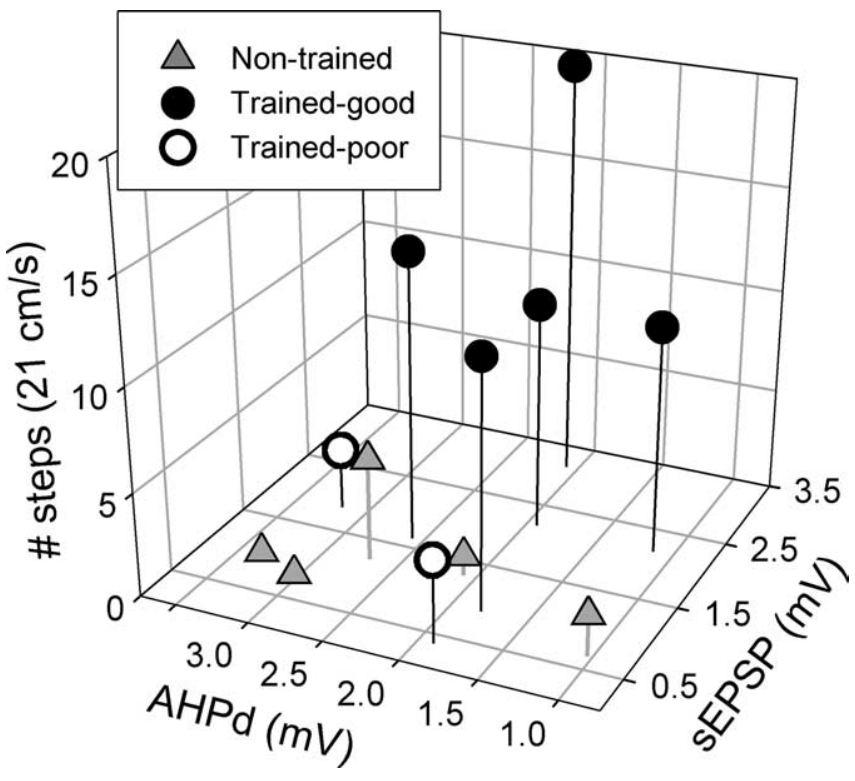

Figure 6. The relationship of behavioral and electrophysiological measures is demonstrated for rats in the neonatal-transected nontrained, trained good-stepper, and trained poor-stepper groups. Rats with the best stepping capacity tended to have both large sEPSP and small AHPd. Rats with poor-stepping capacity displayed values of sEPSP and AHPd similar to nontrained rats.

Training success after neonatal spinal transection is correlated with changes in electrophysiological parameters The success of training was evaluated quantitatively by counting the number of steps the rat could take during a $10 \mathrm{~s}$ treadmill test session at $21 \mathrm{~cm} / \mathrm{s}$. A plot of the number of steps as a function of electrophysiological parameters found individually to be affected by successful step training (see above) demonstrates that the most successful training was generally associated with both larger sEPSPs (four of five above the median value) and smaller AHPd (four of five at or below median value) (Fig. 6). We also observed that the two trained poor-steppers resembled the nontrained rats either in AHPd or sEPSP amplitude. The trained poor-steppers also exhibited the smallest mean CEPSP $_{\text {mono }}$ amplitudes of all neonatally injured animals (Table 1), similar to the mean value in rats injured as adults, which are also known to be poor-steppers (Ichiyama et al., 2005). However, successful

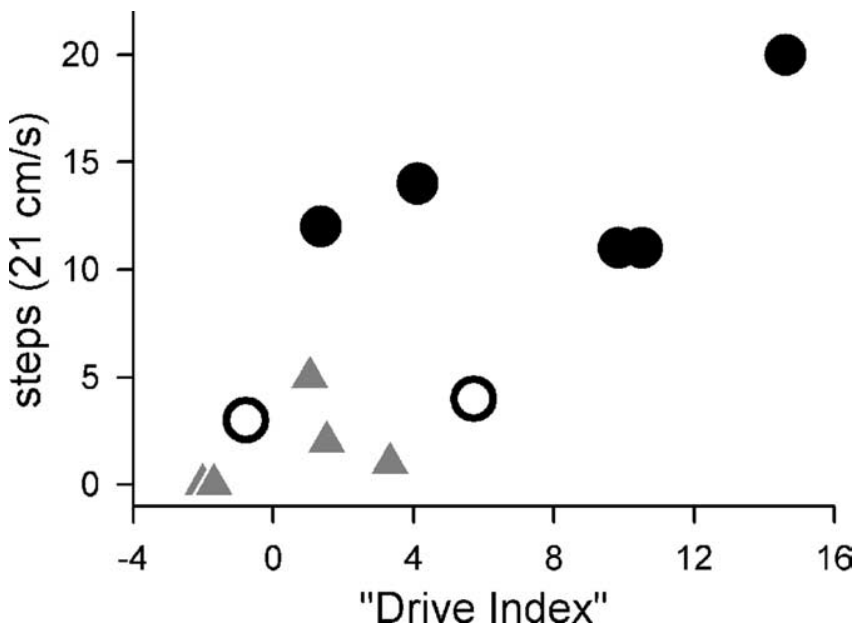

Figure 7. The drive index correlates strongly with the stepping capacity across the different groups. The number of steps taken by each rat during a $10 \mathrm{~s}$ test period is plotted against the drive index for neonatally injured rats. Groups are nontrained (gray triangles), trained goodstepper (filled circles), and trained poor-stepper (open circles).

training did not correlate with a change in the monosynaptic cEPSP (Fig. 5, Table 1) (nontrained vs trained good-stepper; $p>0.6$ ) in contrast to the polysynaptic cEPSP. As pointed out above, the poor-steppers, like the good-steppers, had a large polysynaptic component elicited by VLF stimulation; however, based on time-to-peak of the cEPSP and its facilitation during burst stimulation (Fig. 4), we consider the polysynaptic circuits associated with good and bad stepping performance to be different.

Behavioral and kinematic data suggest that one effect of training is to "enable" intrinsic circuitry or the execution of an intrinsic program. We assume that one component of such a program is the ability to bring motoneurons to threshold when the correct drive is delivered by the central pattern generator. The three variables involving motoneuron activity that were most affected by successful training were sEPSP, AHPd, and cEPSP poly $_{\text {(Figs. 5, 6; }}$ Table 1). We therefore considered whether a linear combination of these variables (mean value for each rat) is correlated with stepping ability in the different preparations. When these three factors were linearly regressed against the number of steps (in 

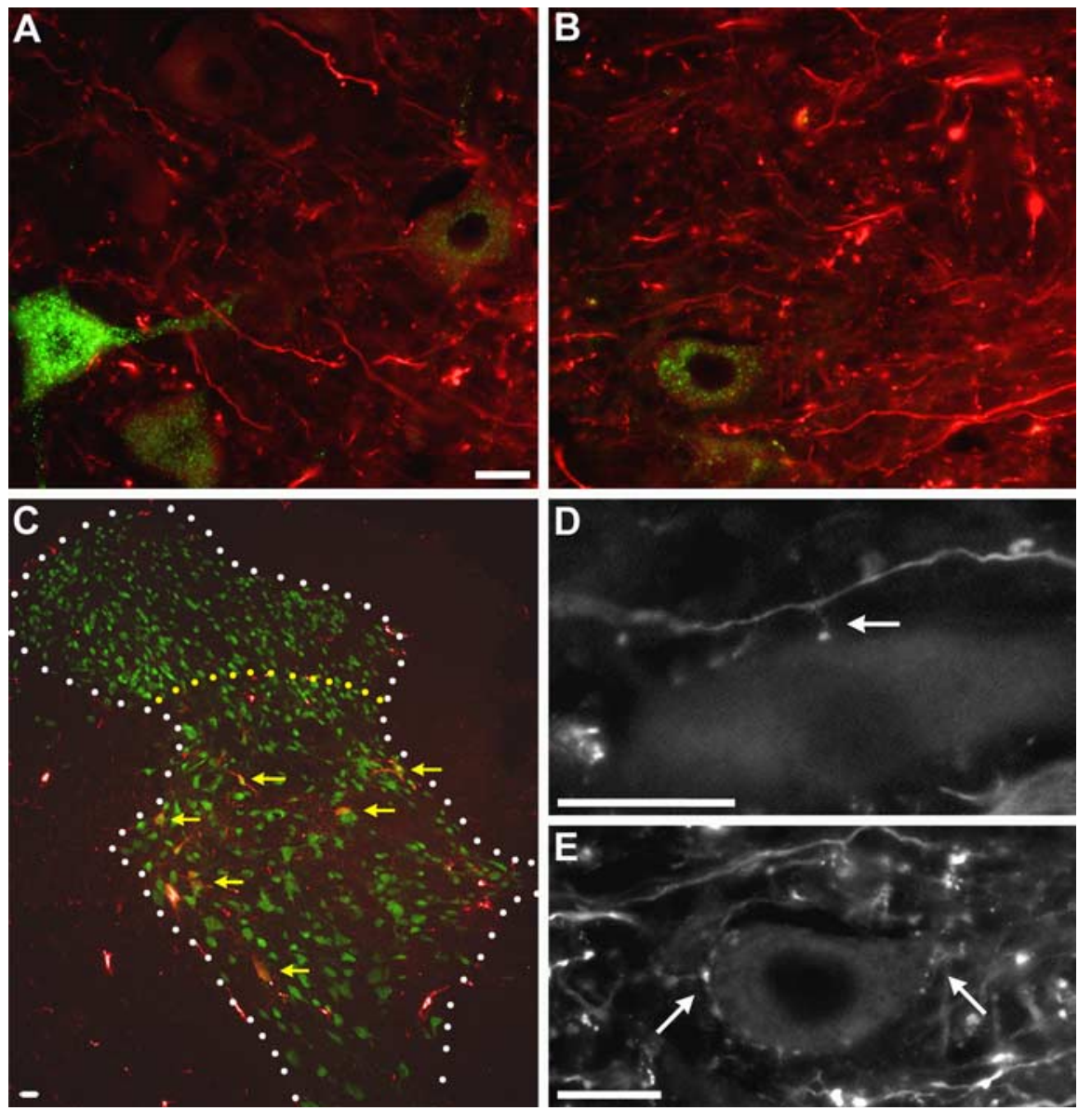

Figure 8. Anatomical tracing demonstrates projections to the $M G$ motoneuron pool. $A, B$, Assay 1 demonstrates axons in the $L 5$ ventral horn labeled from the ipsilateral VLF at T11 (red; injection site similar to VLF electrode site). Many appear to have projections onto MG motoneurons (green). A lower-power example is shown in supplemental Figure 3 (available at www. jneurosci.org as supplemental material). Animals injured as neonates $(\boldsymbol{B})$ appear to have more labeled axons projecting into the region of the MG motoneurons than those injured as adults $(\boldsymbol{A})$ (see Results). Some of these projections are in close apposition to motoneuron cell bodies and dendrites and have swellings suggestive of synaptic contacts (arrows in $\boldsymbol{D}$ and $\boldsymbol{E}$ ). $\boldsymbol{C}$, Assay 2 demonstrates that neurons retrogradely labeled (red; yellow arrows) from their projection to the $L 5$ ventral horn (area of $M G$ motoneuron pool) were concentrated in laminas VI-IX of the lower thoracic cord (area of VLF stimulation). The ipsilateral gray matter is outlined with white dots and neurons labeled with NeuN (green). The yellow dotted line delineates the general separation between laminas IV and V. The lateral edge of the cord is left, dorsal is top, and midline is right. Scale bars, $20 \mu \mathrm{m}$.

neonatal-TX animals) with a "best fit" algorithm (SigmaStat $3.0)$, the resulting equation was: number of steps $=[(5.6 \times$ sEPSP $\left.)+\left(2.7 \times \mathrm{cEPSP}_{\text {poly }}\right)-(2.2 \times \mathrm{AHPd})\right]$. Stepping ability (number of steps) was significantly correlated with this "drive index" $\left(r^{2}=0.53 ; p<0.001\right)$ (Fig. 7).

\section{Anatomy}

We used anatomical methods to determine whether the VLF input to motoneurons caudal to spinal transection that we observed in electrophysiological experiments is composed of ascending axons activated antidromically, propriospinal descending axons originating caudal to the transection and surviving the injury, or both. We also aimed to assess whether there were any anatomical differences in VLF projections in neonatally transected and adult transected cord into the motoneuron pool that might correspond to the differences we observed electro-

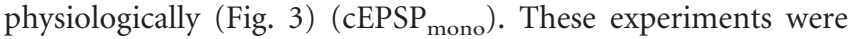
performed in rats that received a complete spinal transection but without training.
Assay 1

To determine the location of cell bodies of origin of ascending VLF axons and to determine whether axons traveling in the VLF had collaterals that projected into the L4/5 ventral horn, dextran-594 was injected where the VLF stimulating microelectrode would have been placed in electrophysiological experiments. As with electrophysiological experiments, we examined animals injured either as neonates $(\mathrm{P} 5 ; n=4)$ or as young adults (5 weeks; $n=3)$ to determine whether there were anatomical differences, because their response to step training differs substantially (Ichiyama et al., 2005). The general pattern of labeling appeared similar between the two groups with stained neurons in all segments between T10/11 and L4/5. Importantly, for this work, many neurons were located near MG motoneurons (identified by retrograde transport of dextran-LY from the left MG muscle). Labeled axons were also present in the vicinity of motoneurons, and many of these axons appeared in close apposition to labeled MG processes and somata and displayed synapse-like boutons (Fig. 8D,E). These axons are likely to contribute to the VLF monosynaptic projections measured electrophysiologically.

As shown above, the mean amplitude of the VLF-elicited monosynaptic EPSP $\left(\mathrm{cEPSP} \mathrm{Pono}_{\text {mos }}\right)$ wignificantly smaller in animals injured as adults than as neonates (Fig. 3, Table 1). Correspondingly, although both groups displayed labeled axons near MG motoneurons, they appeared more abundant in animals injured as neonates than in those injured as young adults (Fig. $8 A, B$ ). This qualitative assessment was confirmed by quantitative image analysis. The percentage of a uniform area around labeled MG motoneurons occupied by VLF-labeled axons (i.e., their projection density) was significantly greater in adult animals injured as neonates than in those injured as adults (overall means, $12.9 \pm$ $1.4, n=4$ vs $5.7 \pm 1.7, n=3 ; p<0.002)$. These differences occurred despite the greater labeling in VLF for adults compared with neonates (overall means, $31.3 \pm 5.3$ vs $19.3 \pm 1.8$ ) (supplemental Fig. 3, available at www.jneurosci.org as supplemental material). Together, these findings suggest greater plasticity in the VLF projection to the lumbar gray matter in rats transected as neonates than in those transected as adults. This difference in plasticity may account for the greater success of step training in neonatally injured compared with adult-injured animals.

\section{Assay 2}

To determine the location of cell bodies of axons projecting from caudal thoracic segments to the hindlimb motoneuron pools, injections of dextran-594 were made into the L5 ventral horn of animals spinalized as young adults $(n=3)$. Injections revealed a cell column extending to the VLF electrode region (T10/11) and 
rostral, some of which had processes extending laterally into the white matter. In agreement with previous work (Menetrey et al., 1985), the number of neurons per segment appeared to decrease with distance from the L5 injection site. Neurons were concentrated in intermediate laminas, especially lamina VII, known to contain locomotor interneurons (Carr et al., 1995; MacLean et al., 1995; Cina and Hochman, 2000; Ahn et al., 2005) (Fig. 8C). Together, these different tracer experiments indicate that both ascending and descending fibers might have contributed to the response of motoneurons to stimulation of the VLF after chronic spinal transection.

\section{Discussion}

Improved stepping behavior after training spinal-injured animals has been reported previously (Barbeau and Rossignol, 1987; de Leon et al., 1998a; Multon et al., 2003; Edgerton et al., 2004; Timoszyk et al., 2005). Training success in the present experiments was measured primarily by the number of steps the rat could take on the treadmill at a speed of $21 \mathrm{~cm} / \mathrm{s}$. Other manifestations were the rat's ability to lift its foot by flexing its knee and the coordination between the ankle, knee, and hip joints. Our findings relate improvements in stepping to changes in electrophysiological variables obtained in the same rats. The common denominator of the electrophysiological changes is the susceptibility of motoneurons to discharge. Motoneurons are more likely to discharge if EPSP amplitude increases and AHPd decreases. If both occurred, as indicated by the drive index, stepping was facilitated (Figs. 6, 7). If only one occurred, stepping was poor, even after training. The combined electrophysiological parameters were highly predictive of stepping capacity, although the total change in cellular and synaptic properties leading to enhanced stepping capacity is certainly much more complex than what is expressed by the index.

Trained good-steppers showed significantly more consistent joint coordination for the best leg (PXC values) than untrained animals. Moreover, stepping kinematics were best in the trained good-stepper group (WR values), although the differences reached significance only for the right leg. Successful stepping was distinguished from unsuccessful stepping by the ability to generate higher-frequency movements, more consistent coordination among joints, and to a lesser extent by the ability to generate movement around individual joints. The better performance of right leg relative to left leg for trained good-steppers and of knee joint over ankle joint also suggests that our electrophysiological assessment (ankle extensors on the left side) of these animals yields conservative estimates of the differences between trained and nontrained groups.

The minimal change in many step parameters after treadmill training indicates that the training regimen enabled an already existing motor program for stepping, increasing the number of steps, possibly with secondary effects on the quality and coordination of the step components. Reduction by training of molecular markers of inhibitory synapses (GAD67) after training (Tillakaratne et al., 2002) supports the proposition that training "enables" execution of an intrinsic program. It is uncertain whether these changes are required for successful step training or whether they are a consequence of other adjustments that are responsible for the development of stepping ability. Training itself was not responsible for the electrophysiological changes, because these were limited if training was unsuccessful.

The anatomical studies suggest that the VLF-induced response of motoneurons most likely reflects a combination of orthodromic (descending fibers) and antidromic (ascending fi- bers) inputs, but their relative contribution is unknown. The VLF-evoked monosynaptic EPSPs were considerably smaller after adult than neonatal transection, surprising in that more VLFprojecting neurons might have degenerated after axotomy in neonates than in adults (Bregman and Goldberger, 1982; Sheard et al., 1984). One possible explanation is that surviving VLF fibers may be more prone to plastic changes (e.g., sprouting) after spinal transection in neonates than adults. The greater density of VLF-traced axons in the ventral cord of animals injured as neonates supports this proposition. We did not examine trainingrelated anatomical differences, but training after spinal transection has been shown to affect motoneuron structure (Gazula et al., 2004).

Enhancement of group Ia fiber-evoked monosynaptic EPSPs (sEPSP) after training differs from the report of reduced Iaevoked EPSPs in trained adult cats (Cote et al., 2003). These were attributed to a higher level of presynaptic inhibition hypothesized to "help reduce spasticity by decreasing Ia transmission and improve phase-dependent modulation of the stretch reflexes during stepping." They also suggested that the group Ib (Golgi tendon organ) projection to motoneurons may be an important target of the training regimen, because treatment with clonidine [a noradrenergic $\alpha 2$ agonist that improves stepping (Chau et al., 1998)] reverses the sign of group Ib disynaptic input to homonymous motoneurons from inhibition to excitation more frequently in trained than in nontrained cats. Such findings in adult cats suggest that in the absence of the robust plasticity characteristic of neonates, other strategies/mechanisms may be used. However, differences between species and/or injury levels may also account for some of the differences between our results and those reported in adult cat (Munson et al., 1986; Hochman and McCrea, 1994a,b).

We have also shown that AHP depth is strongly correlated with the success of stepping behavior. The motoneuron AHP tends to depress high-frequency firing and thus any decrease in its amplitude with training would enhance the ability of motoneurons to produce bursts required for the muscle to exert tetanic forces. The peak of the AHP occurs at a latency of $\sim 15 \mathrm{~ms}$ from the onset of the spike in intact rats, equivalent to a firing frequency of $70 \mathrm{~Hz}$, and $18 \mathrm{~ms}$ in neonatally injured rats $(56 \mathrm{~Hz})$, well within the functional frequency range of rat motoneuron firing (Gorassini et al., 2000). Reducing AHP amplitude would also increase the probability of doublet firing and thus the force exerted by the muscle (Grottel and Celichowski, 1999). AHPd can also be modified in rats injured as adults, where passive exercise returns AHPd toward normal (Beaumont et al., 2004). In addition, it has been shown both experimentally and in modeling studies that alteration of AHP amplitude in spinal interneurons affects the duration of the locomotor rhythm and burst intensity in individual interneurons (Wallen et al., 1992). Restoring AHP values toward normal is thus likely an important component of reestablishing normal stepping behavior.

The mechanism of AHPd regulation here is not known, although reduction of AHPd by serotonin application has been shown in other systems (Van Dongen et al., 1986; Wallen et al., 1992; Bayliss et al., 1995). Thus, reduction of 5-HT by a complete spinal transection (Clineschmidt et al., 1971; Hadjiconstantinou et al., 1984; Steward et al., 2006) should cause motoneuron AHP to become larger, as we found. 5-HT would likely exert such an influence not only on motoneurons but interneurons as well (Van Dongen et al., 1986; Parker and Grillner, 1999; Kozlov et al., 2001; Schwartz et al., 2005; Biro et al., 2006; Zhong et al., 2006a,b), possibly with great functional effect (Rossignol et al., 
2001). For example, in systems disrupted by previous neonatal spinal transection, activation of 5-HT receptors can restore alternating patterned hindlimb behavior (Norreel et al., 2003) and rapidly facilitate stepping ability (but see Kim et al., 1999; Fong et al., 2005). Alternatively, it is possible that not all serotonergic influence is lost after transection (Clineschmidt et al., 1971; Hadjiconstantinou et al., 1984; Newton et al., 1986; Newton and Hamill, 1988) and that training somehow influences these inputs, or that other neurotransmitter systems play a role in AHP modulation (Schotland et al., 1995). Recently, Miles et al. (2007) have demonstrated that muscarinic receptors on motoneurons are activated by cholinergic C-type synaptic boutons, and this reduces AHP amplitude. Reduction of C-type bouton activity after transection with an increase after training could contribute to the findings reported here.

Successful training did not alter the monosynaptic VLF input (cEPSP) but did enhance both the amplitude of cEPSP poly $_{\text {and the }}$ proportion of motoneurons receiving this input, an effect similar to that reported recently using other methods (Lavrov et al., 2006). However, training susceptibility was associated with larger VLF monosynaptic input. Amplitude of the monosynaptic cEPSP in the trained poor-stepping rats was the smallest of any neonatally injured group and was similar to that of rats injured as adults, which are resistant to training (Ichiyama et al., 2005). Facilitation of the $\mathrm{cEPSP}_{\text {poly }}$ during high-frequency stimulation was greatest in the trained poor-stepper rats but was similar between intact, neonatal-injured trained good-stepper and nontrained groups. However, different time-to-peak of the cEPSP in poor- and good-steppers indicates different interneuronal pathways were involved in the VLF projection to motoneurons. These findings underscore the importance of interneuronal pathways from VLF to motoneurons in addition to monosynaptic projections in determining the success of step training.

The transient presence of lesions on the hindpaws of the poorsteppers suggests that noxious input during training, which almost certainly continued in the home cage, may have induced synaptic changes within the lumbar cord that interfered with the effectiveness of training. Such changes may have involved the spinothalamic tract, a major source of ascending nociceptive information, which travels in the VLF. It is known that even brief noxious input can significantly interfere with the effects of training at the spinal level for long periods (Grau et al., 1998, 2004; Crown et al., 2002a,b; Ferguson et al., 2006). This putative effect of noxious cutaneous input is perhaps not surprising in light of the significant role that cutaneous input plays in locomotion (Bouyer and Rossignol, 2003; Fallon et al., 2005).

An intriguing question is the mechanism by which training affects these electrophysiological variables. Considering first the strengthening of the sEPSP, it is known that muscle spindle afferents are very active during stepping movements (Loeb and Duysens, 1979; Prochazka et al., 1979) and that strengthening of synaptic connections can occur via synchronized firing of the presynaptic and postsynaptic neurons (Gustafsson et al., 1987). This strengthening involves the action of NMDA receptors known to be functional on motoneurons, particularly in neonates (Ziskind-Conhaim, 1990; Arvanian et al., 2004). Furthermore, motoneuron NMDA receptor activation is enhanced by administration of the neurotrophins NT-3 and BDNF (Arvanov et al., 2000; Arvanian and Mendell, 2001), both of which are elevated in hindlimb muscle and/or spinal cord by step training (Gomez-Pinilla et al., 2001; Hutchinson et al., 2004). Recent evidence indicates that joint treatment with BDNF and NT-3 is able to improve stepping ability to the same degree as treadmill train- ing alone in spinal cats, although the combination yields the best results (Boyce et al., 2005).

The most unique finding in this work is that electrophysiological characteristics of motoneurons and their synaptic input in spinal transected rats are correlated with the success of treadmill step training. More studies linking the outcome of training and changes in the spinal cord on an animal by animal basis are necessary, because training does not guarantee a specific behavioral outcome. Such experiments, in association with examination of other factors such as neurotrophic factors, density of inhibitory synapses, etc., will provide, in the long run, the best understanding of why training is an important mode of therapy to achieve recovery of function after spinal cord injury. Furthermore, an understanding of the cellular mechanisms underlying successful step training and the factors that interfere with training may provide important guides to optimize recovery from spinal cord injury.

\section{References}

Ahn SN, Guu JJ, Tobin AJ, Edgerton VR, Tillakaratne NJ (2005) Use of c-fos to identify activity-dependent spinal neurons after stepping in intact adult rats. Spinal Cord 44:547-559.

Arvanian VL, Mendell LM (2001) Acute modulation of synaptic transmission to motoneurons by BDNF in the neonatal rat spinal cord. Eur J Neurosci 14:1800-1808.

Arvanian VL, Bowers WJ, Petruska JC, Motin V, Manuzon H, Narrow WC, Federoff HJ, Mendell LM (2004) Viral delivery of NR2D subunits reduces $\mathrm{Mg} 2+$ block of NMDA receptor and restores NT-3-induced potentiation of AMPA-kainate responses in maturing rat motoneurons. J Neurophysiol 92:2394-2404.

Arvanov VL, Seebach BS, Mendell LM (2000) NT-3 evokes an LTP-like facilitation of AMPA/kainate receptor-mediated synaptic transmission in the neonatal rat spinal cord. J Neurophysiol 84:752-758.

Barbeau H, Rossignol S (1987) Recovery of locomotion after chronic spinalization in the adult cat. Brain Res 412:84-95.

Bayliss DA, Umemiya M, Berger AJ (1995) Inhibition of N- and P-type calcium currents and the after-hyperpolarization in rat motoneurones by serotonin. J Physiol (Lond) 485:635-647.

Beaumont E, Houle JD, Peterson CA, Gardiner PF (2004) Passive exercise and fetal spinal cord transplant both help to restore motoneuronal properties after spinal cord transection in rats. Muscle Nerve 29:234-242.

Biro Z, Hill RH, Grillner S (2006) 5-HT Modulation of identified segmental premotor interneurons in the lamprey spinal cord. J Neurophysiol 96:931-935.

Bouyer LJ, Rossignol S (2003) Contribution of cutaneous inputs from the hindpaw to the control of locomotion. II. Spinal cats. J Neurophysiol 90:3640-3653.

Boyce VS, Tumolo MA, Murray M, Fisher I, Lemay MA (2005) Neurotrophic factors restore locomotor ability in chronic spinal cats without locomotor training. Soc Neurosci Abstr 35:224.10.

Bregman BS, Goldberger ME (1982) Anatomical plasticity and sparing of function after spinal cord damage in neonatal cats. Science 217:553-555.

Burke-Hubbard B (1998) The world according to wavelets, Ed 2. Wellesley, MA: AK Peters.

Carr PA, Huang A, Noga BR, Jordan LM (1995) Cytochemical characteristics of cat spinal neurons activated during fictive locomotion. Brain Res Bull 37:213-218.

Chau C, Barbeau H, Rossignol S (1998) Effects of intrathecal alpha1- and alpha2-noradrenergic agonists and norepinephrine on locomotion in chronic spinal cats. J Neurophysiol 79:2941-2963.

Cina C, Hochman S (2000) Diffuse distribution of sulforhodamine-labeled neurons during serotonin-evoked locomotion in the neonatal rat thoracolumbar spinal cord. J Comp Neurol 423:590-602.

Clineschmidt BV, Pierce JE, Lovenberg W (1971) Tryptophan hydroxylase and serotonin in spinal cord and brain stem before and after chronic transection. J Neurochem 18:1593-1596.

Cote MP, Gossard JP (2004) Step training-dependent plasticity in spinal cutaneous pathways. J Neurosci 24:11317-11327.

Cote MP, Menard A, Gossard JP (2003) Spinal cats on the treadmill: changes in load pathways. J Neurosci 23:2789-2796. 
Crown ED, Ferguson AR, Joynes RL, Grau JW (2002a) Instrumental learning within the spinal cord: IV. Induction and retention of the behavioral deficit observed after noncontingent shock. Behav Neurosci 116:1032-1051.

Crown ED, Ferguson AR, Joynes RL, Grau JW (2002b) Instrumental learning within the spinal cord. II. Evidence for central mediation. Physiol Behav 77:259-267.

de Leon RD, Hodgson JA, Roy RR, Edgerton VR (1998a) Locomotor capacity attributable to step training versus spontaneous recovery after spinalization in adult cats. J Neurophysiol 79:1329-1340.

De Leon RD, Hodgson JA, Roy RR, Edgerton VR (1998b) Full weightbearing hindlimb standing following stand training in the adult spinal cat. J Neurophysiol 80:83-91.

De Leon RD, Hodgson JA, Roy RR, Edgerton VR (1999) Retention of hindlimb stepping ability in adult spinal cats after the cessation of step training. J Neurophysiol 81:85-94.

Edgerton VR, Tillakaratne NJ, Bigbee AJ, de Leon RD, Roy RR (2004) Plasticity of the spinal neural circuitry after injury. Annu Rev Neurosci 27:145-167.

Fallon JB, Bent LR, McNulty PA, Macefield VG (2005) Evidence for strong synaptic coupling between single tactile afferents from the sole of the foot and motoneurons supplying leg muscles. J Neurophysiol 94:3795-3804.

Ferguson AR, Crown ED, Grau JW (2006) Nociceptive plasticity inhibits adaptive learning in the spinal cord. Neuroscience 141:421-431.

Fong AJ, Cai LL, Otoshi CK, Reinkensmeyer DJ, Burdick JW, Roy RR, Edgerton VR (2005) Spinal cord-transected mice learn to step in response to quipazine treatment and robotic training. J Neurosci 25:11738-11747.

Gardiner PF (1993) Physiological properties of motoneurons innervating different muscle unit types in rat gastrocnemius. J Neurophysiol 69:1160-1170.

Gardiner PF, Kernell D (1990) The "fastness" of rat motoneurones: timecourse of afterhyperpolarization in relation to axonal conduction velocity and muscle unit contractile speed. Pflügers Arch 415:762-766.

Gazula VR, Roberts M, Luzzio C, Jawad AF, Kalb RG (2004) Effects of limb exercise after spinal cord injury on motor neuron dendrite structure. J Comp Neurol 476:130-145.

Gomez-Pinilla F, Ying Z, Opazo P, Roy RR, Edgerton VR (2001) Differential regulation by exercise of BDNF and NT-3 in rat spinal cord and skeletal muscle. Eur J Neurosci 13:1078-1084.

Gorassini M, Eken T, Bennett DJ, Kiehn O, Hultborn H (2000) Activity of hindlimb motor units during locomotion in the conscious rat. J Neurophysiol 83:2002-2011.

Grau JW, Barstow DG, Joynes RL (1998) Instrumental learning within the spinal cord: I. Behavioral properties. Behav Neurosci 112:1366-1386.

Grau JW, Washburn SN, Hook MA, Ferguson AR, Crown ED, Garcia G, Bolding KA, Miranda RC (2004) Uncontrollable stimulation undermines recovery after spinal cord injury. J Neurotrauma 21:1795-1817.

Grillner S (2002) The spinal locomotor CPG: a target after spinal cord injury. Prog Brain Res 137:97-108.

Grottel K, Celichowski J (1999) The influence of changes in the stimulation pattern on force and fusion in motor units of the rat medial gastrocnemius muscle. Exp Brain Res 127:298-306.

Gustafsson B, Wigstrom H, Abraham WC, Huang YY (1987) Long-term potentiation in the hippocampus using depolarizing current pulses as the conditioning stimulus to single volley synaptic potentials. J Neurosci 7:774-780.

Hadjiconstantinou M, Panula P, Lackovic Z, Neff NH (1984) Spinal cord serotonin: a biochemical and immunohistochemical study following transection. Brain Res 322:245-254.

Harkema SJ (2001) Neural plasticity after human spinal cord injury: application of locomotor training to the rehabilitation of walking. Neuroscientist 7:455-468.

Hochman S, McCrea DA (1994a) Effects of chronic spinalization on ankle extensor motoneurons. I. Composite monosynaptic Ia EPSPs in four motoneuron pools. J Neurophysiol 71:1452-1467.

Hochman S, McCrea DA (1994b) Effects of chronic spinalization on ankle extensor motoneurons. II. Motoneuron electrical properties. J Neurophysiol 71:1468-1479.

Hutchinson KJ, Gomez-Pinilla F, Crowe MJ, Ying Z, Basso DM (2004) Three exercise paradigms differentially improve sensory recovery after spinal cord contusion in rats. Brain 127:1403-1414.

Ichiyama RM, Gerasimenko YP, Zhong H, Roy RR, Edgerton VR (2005)
Hindlimb stepping movements in complete spinal rats induced by epidural spinal cord stimulation. Neurosci Lett 383:339-344.

Joynes RL, de Leon RD, Tillakaratne NJK, Roy RR, Tobin AJ, Edgerton VR (1999) Recovery of locomotion in rats after neonatal spinal transection is not attributable to growth across the lesion. Soc Neurosci Abstr 29:467.18.

Kim D, Adipudi V, Shibayama M, Giszter S, Tessler A, Murray M, Simansky KJ (1999) Direct agonists for serotonin receptors enhance locomotor function in rats that received neural transplants after neonatal spinal transection. J Neurosci 19:6213-6224.

Kozlov A, Kotaleski JH, Aurell E, Grillner S, Lansner A (2001) Modeling of substance $\mathrm{P}$ and 5-HT induced synaptic plasticity in the lamprey spinal CPG: consequences for network pattern generation. J Comp Neurosci 11:183-200.

Kubasak MD, Hedlund E, Roy RR, Carpenter EM, Edgerton VR, Phelps PE (2005) L1 CAM expression is increased surrounding the lesion site in rats with complete spinal cord transection as neonates. Exp Neurol 194:363-375.

Lavrov I, Gerasimenko YP, Ichiyama RM, Courtine G, Zhong H, Roy RR, Edgerton VR (2006) Plasticity of spinal cord reflexes after a complete transection in adult rats: relationship to stepping ability. J Neurophysiol 96:1699-1710.

Loeb GE, Duysens J (1979) Activity patterns in individual hindlimb primary and secondary muscle spindle afferents during normal movements in unrestrained cats. J Neurophysiol 42:420-440.

MacLean JN, Hochman S, Magnuson DS (1995) Lamina VII neurons are rhythmically active during locomotor-like activity in the neonatal rat spinal cord. Neurosci Lett 197:9-12.

Menetrey D, de Pommery J, Roudier F (1985) Propriospinal fibers reaching the lumbar enlargement in the rat. Neurosci Lett 58:257-261.

Miles GB, Hartley R, Todd AJ, Brownstone RM (2007) Spinal cholinergic interneurons regulate the excitability of motoneurons during locomotion Proc Natl Acad Sci USA 104:2448-2453.

Multon S, Franzen R, Poirrier AL, Scholtes F, Schoenen J (2003) The effect of treadmill training on motor recovery after a partial spinal cord compression-injury in the adult rat. J Neurotrauma 20:699-706.

Munson JB, Foehring RC, Lofton SA, Zengel JE, Sypert GW (1986) Plasticity of medial gastrocnemius motor units following cordotomy in the cat. J Neurophysiol 55:619-634.

Newton BW, Hamill RW (1988) The morphology and distribution of rat serotoninergic intraspinal neurons: an immunohistochemical study. Brain Res Bull 20:349-360.

Newton BW, Maley BE, Hamill RW (1986) Immunohistochemical demonstration of serotonin neurons in autonomic regions of the rat spinal cord. Brain Res 376:155-163.

Norreel JC, Pflieger JF, Pearlstein E, Simeoni-Alias J, Clarac F, Vinay L (2003) Reversible disorganization of the locomotor pattern after neonatal spinal cord transection in the rat. J Neurosci 23:1924-1932.

Parker D, Grillner S (1999) Activity-dependent metaplasticity of inhibitory and excitatory synaptic transmission in the lamprey spinal cord locomotor network. J Neurosci 19:1647-1656.

Petruska JC, Ichiyama RM, Crown ED, Tansey KE, Edgerton VR, Mendell LM (2004) Segmental and central inputs to motoneurons change following spinal cord transection and step training in rats. Soc Neurosci Abstr 34:418.10.

Prochazka A, Stephens JA, Wand P (1979) Muscle spindle discharge in normal and obstructed movements. J Physiol (Lond) 287:57-66.

Rossignol S (2000) Locomotion and its recovery after spinal injury. Curr Opin Neurobiol 10:708-716.

Rossignol S, Giroux N, Chau C, Marcoux J, Brustein E, Reader TA (2001) Pharmacological aids to locomotor training after spinal injury in the cat. J Physiol (Lond) 533:65-74.

Roy RR, Acosta Jr L (1986) Fiber type and fiber size changes in selected thigh muscles six months after low thoracic spinal cord transection in adult cats: exercise effects. Exp Neurol 92:675-685.

Roy RR, Talmadge RJ, Hodgson JA, Zhong H, Baldwin KM, Edgerton VR (1998) Training effects on soleus of cats spinal cord transected (T12-13) as adults. Muscle Nerve 21:63-71.

Roy RR, Talmadge RJ, Hodgson JA, Oishi Y, Baldwin KM, Edgerton VR (1999) Differential response of fast hindlimb extensor and flexor muscles to exercise in adult spinalized cats. Muscle Nerve 22:230-241.

Schotland J, Shupliakov O, Wikstrom M, Brodin L, Srinivasan M, You ZB, 
Herrera-Marschitz M, Zhang W, Hokfelt T, Grillner S (1995) Control of lamprey locomotor neurons by colocalized monoamine transmitters. Nature 374:266-268.

Schwartz EJ, Gerachshenko T, Alford S (2005) 5-HT prolongs ventral root bursting via presynaptic inhibition of synaptic activity during fictive locomotion in lamprey. J Neurophysiol 93:980-988.

Seburn K, Coicou C, Gardiner P (1994) Effects of altered muscle activation on oxidative enzyme activity in rat alpha-motoneurons. J Appl Physiol 77:2269-2274.

Sheard P, McCaig CD, Harris AJ (1984) Critical periods in rat motoneuron development. Dev Biol 102:21-31.

Steward O, Sharp K, Selvan G, Hadden A, Hofstadter M, Au E, Roskams J (2006) A re-assessment of the consequences of delayed transplantation of olfactory lamina propria following complete spinal cord transection in rats. Exp Neurol 198:483-499.

Tillakaratne NJ, de Leon RD, Hoang TX, Roy RR, Edgerton VR, Tobin AJ (2002) Use-dependent modulation of inhibitory capacity in the feline lumbar spinal cord. J Neurosci 22:3130-3143.

Timoszyk WK, Nessler JA, Acosta C, Roy RR, Edgerton VR, Reinkensmeyer DJ, de Leon R (2005) Hindlimb loading determines stepping quantity and quality following spinal cord transection. Brain Res 1050:180-189.

Van Dongen PA, Grillner S, Hokfelt T (1986) 5-Hydroxytryptamine (serotonin) causes a reduction in the afterhyperpolarization following the action potential in lamprey motoneurons and premotor interneurons. Brain Res 366:320-325.

Wallen P, Ekeberg O, Lansner A, Brodin L, Traven H, Grillner S (1992) A computer-based model for realistic simulations of neural networks. II. The segmental network generating locomotor rhythmicity in the lamprey. J Neurophysiol 68:1939-1950.

Zhong G, Diaz-Rios M, Harris-Warrick RM (2006a) Intrinsic and functional differences among commissural interneurons during fictive locomotion and serotonergic modulation in the neonatal mouse. J Neurosci 26:6509-6517.

Zhong G, Diaz-Rios M, Harris-Warrick RM (2006b) Serotonin modulates the properties of ascending commissural interneurons in the neonatal mouse spinal cord. J Neurophysiol 95:1545-1555.

Ziskind-Conhaim L (1990) NMDA receptors mediate poly- and monosynaptic potentials in motoneurons of rat embryos. J Neurosci 10:125-135. 